\title{
Parenchymal regression in chronic pancreatitis spares islets reprogrammed for the expression of NF $\kappa$ B and IAPs
}

\author{
Cornelia Hasel*, Umesh K Bhanot*, René Heydrich, Jörn Sträter and Peter Möller \\ Department of Pathology, University of Ulm, Ulm, Germany
}

\begin{abstract}
In advanced chronic pancreatitis (CP), islets are preserved even in the midst of scarring. We recently showed in CP local production of interferon (IFN) $\gamma$, transforming growth factor (TGF) $\beta$ and death receptor ligand TRAIL (tumor necrosis factor-related apoptosis-inducing ligand), along with functional death receptor neoexpression and apoptosis in exocrine but not in endocrine cells. However, islets are strongly induced for TRAILreceptor(R)-4 lacking the functional death domain. TRAIL-R4 signaling in T cells induces NF $k B$, which activates antiapoptotic programs. Here, we demonstrate that in insulinoma cells CM, TGF $\beta /$ IFN $\gamma /$ TRAIL in combination induced TRAIL-R4 surface expression. TRAIL/IFN $\gamma$ upregulated NF $\kappa$ B subunits and its target gene survivin while downmodulating I $\kappa \mathrm{B} \alpha$ mRNA. RelA transcriptional activity increased upon stimulation with IFN $\gamma$ and IFN $\gamma /$ TRAIL. In situ, normal pancreatic epithelia had low mRNA levels of NF $k B$ subunits. These were higher in parenchymal areas of CP with severe fibrosis and highest in islets. NF $\kappa$ B-regulated proteins $1 \kappa \mathrm{B} \alpha$, survivin and another apoptosis inhibitor, clAP1, were found in corresponding sites, again at highest levels in islets surrounded by fibrosis. In conclusion, islets in CP not only evade immune attack by nonexposure of functional death receptors in the presence of TRAIL-R4 but also additionally neoexpress NF $\kappa$ B and its target genes, survivin and clAP1, to protect themselves from apoptosis.
\end{abstract}

Laboratory Investigation (2005) 85, 1263-1275. doi:10.1038/labinvest.3700323; published online 22 August 2005

Keywords: chronic pancreatitis; fibrosis; $\mathrm{NF} \kappa \mathrm{B}$; RelA; survivin; clAPs

Chronic pancreatitis (CP) is characterized by a progressive loss and fibrosis of exocrine parenchyma, whereas the endocrine islets remain structurally and functionally intact for a prolonged period of time. ${ }^{1,2}$ The mechanism/s by which islets survive in an adverse environment initially infiltrated by inflammatory cells and, at later stages, by expanding fibrous tissue is largely unknown. Immune evasion might be a major contributory mechanism. We have previously shown that islets express the deathinducing ligand CD95L (FasL) but do not express its receptor CD95 (Fas). In CP, this 'immunoprivileged' status is preserved in endocrine cells, whereas the exocrine epithelia neoexpress CD95 (Fas) along with HLA-DR. ${ }^{3}$ We further showed that islet cells in normal pancreas (NP) are devoid of TRAIL (tumor necrosis factor (TNF)-related apoptosis-inducing ligand) receptors (R), which, like CD95,

Correspondence: Dr P Möller, MD, Department of Pathology, University of Ulm, Albert-Einstein-Allee 11, Ulm D-89081, Germany.

E-mail: peter.moeller@medizin.uni-ulm.de

* These authors contributed equally to this work.

Received 13 April 2005; revised 31 May 2005; accepted 2 June 2005; published online 22 August 2005 are members of the TNF receptor superfamily. In CP, there is an induction and high levels of expression of TRAIL-R1, -R2 and -R4 in exocrine cells. In contrast, islet cells are strongly TRAIL-R4 positive and are essentially devoid of the death signaltransducing TRAIL-R1 and -R2. ${ }^{4}$ TRAIL-R4 lacks the cytoplasmic death domain and was therefore regarded as a decoy receptor. Recent studies carried out in T-lymphocytes, however, hint at an alternative functional role of TRAIL-R4. TRAIL-R4 has been shown to transduce a signal leading to induction of $\mathrm{NF} \kappa \mathrm{B}$ constituents, upon binding of TRAIL. ${ }^{5}$ We identified pancreatic stellate cells (PSCs) producing the fibrogenic cytokine transforming growth factor (TGF) $\beta^{6,7}$ as the major source of TRAIL in CP. ${ }^{4}$ Against this background, it is tempting to speculate that TRAIL, while contributing to exocrine parenchymal damage by TRAIL-R1and -R2-mediated apoptosis, might at the same time signal endocrine cells via TRAIL-R4 in the sense of $\mathrm{NF} \kappa \mathrm{B}$ induction and action. Among the multitude of genes regulated by $\mathrm{NF} \kappa \mathrm{B}$ are antiapoptotic genes such as those for inhibitor of apoptosis proteins (IAPs). ${ }^{8}$ IAPs prevent cell death by binding to and inhibiting active caspases. ${ }^{9}$ This led us to investigate the role of $\mathrm{NF} \kappa \mathrm{B}$ constituents in the context of $\mathrm{CP}$ 
with particular emphasis on the mechanism/s and/ or event/s responsible for islet preservation.

We show here that activated human insulinoma cells CM express TRAIL-R4 in the absence of TRAILR1 and -R2 and, upon TRAIL treatment, express increased amounts of mRNA of $\mathrm{NF} \kappa \mathrm{B}$ subunits and survivin. Treatment with interferon (IFN) $\gamma$ and IFN $\gamma$ plus TRAIL elevated RelA transcription in CM. Furthermore, in $\mathrm{CP}$ we found an induction of $\mathrm{NF} \kappa \mathrm{B}$ subunits in pancreatic epithelia, which, although at low levels in exocrine pancreas, is massive in pancreatic islet cells. The extent of local $\mathrm{NF} \kappa \mathrm{B}$ induction and protein expression correlates with the severity of fibrosis.

Additionally, survivin and cIAP1 were neoexpressed in islets, again most remarkably in the midst of scarring. Thus, our findings suggest that islet cells in CP, in addition to resorting to immune evasion, also activate antiapoptotic programs for survival.

\section{Materials and methods}

\section{Cell Culture}

The human insulinoma cell line CM was obtained from Professor P Pozzilli of St Bartholomew's Hospital, London, UK. The cells were grown in Iscove's modified Dulbecco's medium/RPMI 1640 (4:1) supplemented with $10 \%$ fetal bovine serum, $5 \mathrm{mmol} / \mathrm{l}$ L-glutamine, $100 \mathrm{U} / \mathrm{ml}$ penicillin and $100 \mu \mathrm{g} / \mathrm{ml}$ streptomycin. Cells were maintained at $37^{\circ} \mathrm{C}$ in $5 \% \mathrm{CO}_{2}$.

\section{Assessment of TRAIL-Induced Apoptosis}

Sensitivity of CM cells to TRAIL-mediated apoptosis was determined using $100 \mathrm{ng} / \mathrm{ml}$ of human recombinant Killer $^{\mathrm{TM}}$ TRAIL (Alexis, San Diego, CA, USA) for $6 \mathrm{~h}$. To test for cytokine-enhanced sensitivity of CM cells towards TRAIL-mediated apoptosis, cells were pretreated with $1 \mathrm{ng} / \mathrm{ml}$ TGF $\beta$ (Roche) for $24 \mathrm{~h}$ followed by $500 \mathrm{U} / \mathrm{ml}$ IFN $\gamma$ (Roche) for $18 \mathrm{~h}$. Apoptotic death rates were determined by annexin $\mathrm{V}$ binding using an FITC-labeled mouse anti-human annexin $\mathrm{V}$ monoclonal antibody (mAb) (IgG1 isotype; PharMingen, San Diego, CA, USA) and $2 \mu \mathrm{l}$ propidium iodide $(50 \mathrm{mg} / \mathrm{ml})$. After gating for propidium iodide negativity to exclude dead cells, $10^{5}$ events were examined for each determination. Flow cytometry was performed on a FACScalibur with CellQuest software (Becton Dickinson, Heidelberg, Germany).

\section{Flow Cytometry}

Surface expression of TRAIL-R1, -R2 and -R4 on CM cells was determined by flow cytometric analysis. A total of $10^{6}$ cells/sample were suspended in $50 \mu \mathrm{l}$ FACS medium (phosphate-buffered saline containing $2 \%$ fetal bovine serum, $0.01 \mathrm{~mol} / \mathrm{l}$ HEPES and
$200 \mathrm{ng} / \mathrm{ml}$ sodium azide) and incubated for $1 \mathrm{~h}$ in an equal volume of the appropriate dilution of the mouse mAbs to TRAIL-R1 (clone M272, IgG1 isotype), TRAIL-R2 (clone M412, IgG1 isotype) and TRAIL-R4 (clone M440, IgG2a isotype) kindly provided by Amgen (Thousand Oaks, CA, USA). The mouse anti-human CD3 (clone Leu4, IgG1 isotype) (DAKO, Copenhagen, Denmark) was used as an irrelevant isotype-matched negative control. Cells were washed twice and incubated with $2 \mathrm{ng}$ of FITC-labeled $\mathrm{F}\left(\mathrm{ab}^{\prime}\right)_{2}$ goat anti-mouse immunoglobulins (DAKO) for $30 \mathrm{~min}$ on ice. Finally, cells were washed twice and resuspended in $500 \mu \mathrm{l}$ cold FACS medium containing $1 \mu \mathrm{g} / \mathrm{ml}$ propidium iodide (Sigma). Analysis was restricted to propidium-negative (viable) cells and was performed on a FACSCalibur cytometer with CellQuestPro software.

\section{Pancreatic Tissues}

In all, 18 patients, whose informed consent was obtained prior to surgery, were chosen for this study. A total of 14 patients underwent partial pancreatectomy for CP: 10 were suffering from alcoholic pancreatitis, two had chronic nonalcoholic pancreatitis associated with pancreas divisum, one developed a cyst after initial surgery and one had cryptogenic CP. Sections were subjected to morphometric assessment for the grading of fibrosis (see below). Four patients underwent partial pancreatectomy for pancreas divisum. The specimens of these patients were histopathologically diagnosed as $\mathrm{NP}$ and included in the study as normal controls. All pancreatectomy specimens were immediately transferred to the laboratory where representative tissue samples were snap frozen in liquid nitrogen and kept there until further processing. Other parts of the tissues were stored at $-80^{\circ} \mathrm{C}$, for later use in frozen section immunohistochemistry and laser capture microdissection (LCM).

\section{Grading of Fibrosis}

$\mathrm{NP}$ and CP cases for this study were selected and graded independently by two pathologists (UKB and $\mathrm{CH})$ on hematoxylin and eosin (H\&E)-stained cryosections based on the relative proportions of parenchyma and stromal fibrosis. There was generally good agreement in NP and CP cases with severe fibrosis. However, there was only partial agreement in grading of CP with mild and moderate fibrosis. Total agreement was achieved, however, on reviewing these cases together on a multiheaded discussion microscope. Further, stromal tissue in $\mathrm{NP}$ and the proportion of fibrosis in different cases of CP was accurately quantitated on H\&E-stained cryosections using a light microscope with a video camera (Sony 3CCD) attached to an image capture card in a standard desktop computer with image analysis software (ImageTool, San Antonio, TX, 
USA) to calculate the volume fraction of fibrosis. Per slide 10 different areas were assessed and the extent of fibrosis was then calculated as percentage of fibrosis in mild, $12.4 \pm 1.8 \%$, moderate, $41.2 \pm$ $0.6 \% \%$, severe fibrosis, $73.9 \pm 6 \%$, and that of normal stromal tissue in NP, as $6.3 \pm 1.9 \%$.

\section{Tissue Processing for LCM}

Frozen tissue specimens were cut at $8 \mu \mathrm{m}$ thickness and serial sections transferred to PALM ${ }^{\mathbb{B}}$ MembraneSlides (PALM, Bernried, Germany). Four to 10 tissue sections were required to obtain sufficient number of cells from various cellular compartment of NP and CP with varying grades of fibrosis. Sections were stained with H\&E as follows: slides were immersed in $70 \%$ ethanol for about $10 \mathrm{~min}$ followed by sequential dips in sterile deionized water, Mayer's hematoxylin solution, sterile deionized water, diluted alcoholic eosin, 95\% ethanol and finally dehydrated with three changes of absolute ethanol for 3 min each. Slides were airdried for $5 \mathrm{~min}$ before proceeding for LCM.

\section{LCM}

PALM $^{\circledR}$ Laser Microbeam Microdissection System with Laser Pressure Catapulting and Robocut Software (PALM, Germany) was used for microdissection. Approximately 2000 cells from each epithelial compartments of NP and CP with various grades of fibrosis were microdissected and catapulted into LCM caps with their inner surface coated with a thin layer of inert mineral oil.

\section{RNA Isolation from Microdissected Tissue}

The material from two to three caps was pooled in a single purification column. Total RNA was isolated using Picopure $^{\mathrm{TM}}$ RNA isolation Kit (Arcturus, Mountain View, CA, USA) according to the manufacturer's instructions. Total RNA was qualitatively and quantitatively assessed on RNA LabChip (Agilent, Wilmington, DE, USA) following the manufacturer's instructions. Only those samples with clearly visible ribosomal peaks and $\mathrm{OD}_{280 / 260}$ ratios between 1.6 and 1.8 were further processed.

\section{RNA Isolation from CM Cells}

Human insulinoma cell line CM was used for stimulation experiments. CM $\left(2 \times 10^{5}\right)$ were stimulated with TRAIL, IFN $\gamma$ and TRAIL + IFN $\gamma$ in ideal conditions for $48 \mathrm{~h}$. Exactly the same number of cells kept under identical culture conditions without addition of any substance was used as controls. Total cellular RNA was isolated using the RNeasy RNA isolation system (Qiagen, Valencia, CA, USA) following the manufacturer's recommendations.
RNA was assessed by agarose gel electrophoresis and quantitated by UV absorbance.

\section{RNA Amplification and Semiquantitative Real-Time PCR}

The RiboAmp ${ }^{\mathrm{TM}}$ RNA Amlification Kit was used for amplifying the total RNA from microdissected tissues. The manufacturer's protocol for performing one round of amplification was used. The amount of RNA obtained after amplification was qualitatively and quantitatively assessed using the RNA LabChip (Agilent). RNA $(2.5 \mu \mathrm{g})$ was reversely transcribed into cDNA using Superscript Reverse Transcriptase (Invitrogen), random hexamer primer and addition of an RNase inhibitor following the manufacturer's protocol for expression analysis of various $\mathrm{NF} \kappa \mathrm{B}$ subunits in microdissected tissues. Primers were designed using Primer Express Software (PerkinElmer, Foster City, CA, USA) to meet the following criteria: nonoverlapping primers as close as possible to each other, avoidance of sequences with propensity for dimer formation, low G-C content, avoiding run of nucleotides and a $T_{\mathrm{m}}$ at around $60^{\circ} \mathrm{C}$. The sequences of the primer pairs are shown in Table 1. Primer pairs were purchased from MWG Biotech (Ebersberg, Germany). Cyclophilin expression was chosen as the endogenous control (forward primer: 5'-ATGGTCAACC CCACCGTGT-3'; reverse primer: $5^{\prime}$-TCTGCTGTCTTTGGGACCTTGTC- $3^{\prime}$ ). First, the absence of nonspecific amplification was confirmed by analyzing the PCR amplification products by agarose gel electrophoresis. Amplicons generated from cDNA were also tested against no template control and RNA. In a further step, optimal primer concentrations were selected by mixing primer concentrations from 50 to $900 \mathrm{nmol}$ of each forward and reverse primer. The curves were checked for low $C_{\mathrm{T}}$, fast rising and for confirmation analyzed by agarose gel electrophoresis. Real-time PCR was performed using $4 \mu \mathrm{l}$ cDNA (12.5 ng/ $\mu \mathrm{l}), 4 \mu \mathrm{l}$ primer mix (forward/reverse) at optimal concentrations, $12 \mu \mathrm{l}$ sterile distilled water and $20 \mu \mathrm{l}$ SYBR Green PCR Master Mix (PE Biosystems, Foster City, CA, USA) per reaction. The following cycling conditions were set: $50^{\circ} \mathrm{C}$ for $2 \mathrm{~min}$, denaturation at $95^{\circ} \mathrm{C}$ for $10 \mathrm{~min}$, followed by 45 cycles at $95^{\circ} \mathrm{C}$ for $20 \mathrm{~s}$ each, $60^{\circ} \mathrm{C}$ for $20 \mathrm{~s}$ and $72^{\circ} \mathrm{C}$ for $20 \mathrm{~s}$. Gene expression of $\mathrm{NF} \kappa \mathrm{B}$ subunits of tissue affected by $\mathrm{CP}$ was measured relative to whole NP tissue as the calibrator sample. All quantitations were also normalized to cyclophilin as an endogenous control to account for variability in the initial concentration of total RNA. Analysis of quantitation was carried out by calculating as follows: 1 . mean $C_{\mathrm{T}}$ value of three replicates per sample; 2 . difference between mean $C_{\mathrm{T}}$ values of samples for each target (CP) and those of the endogenous controls $\left(\Delta C_{\mathrm{T}}\right) ; 3$. difference between mean $C_{\mathrm{T}}$ values of the samples for each target (CP) and the mean $C_{\mathrm{T}}$ value of the correspond- 
Table 1 Sequence and concentration of primers

\begin{tabular}{|c|c|c|c|}
\hline Gene & Primer & Sequence & Concentration (nM) \\
\hline \multirow[t]{2}{*}{ RelA } & Forward & 5'-TCA TGA AGA AGA GTC CTT TCA-3' & 900 \\
\hline & Reverse & 5'-TGA TCT GCC CAG AAG GAA ACA-3' & 900 \\
\hline \multirow[t]{2}{*}{$\mathrm{NF} \kappa \mathrm{B} 1$} & Forward & 5'-ACA ACA TCT CAT TGG CAG GCT-3' & 900 \\
\hline & Reverse & 5'-GGT CAT AGA GAG GCT CAA AGT-3' & 900 \\
\hline \multirow[t]{2}{*}{$\mathrm{NF} \kappa \mathrm{B} 2$} & Forward & 5'-GAT GGA TCT GAG TAT AGT GCG-3' & 300 \\
\hline & Reverse & 5'-CCG GAG ATT TGC TAT CAT GGA-3' & 900 \\
\hline \multirow[t]{2}{*}{ c-Rel } & Forward & 5'-CCT GTT GTC TCG AAC CCA AT-3' & 300 \\
\hline & Reverse & $5^{\prime}$-TCC CAA TCG TTC AAC ACA AA-3' & 900 \\
\hline \multirow[t]{2}{*}{ RelB } & Forward & $5^{\prime}$-ATC TGC TTC CAG GCC TCA TAT-3' & 300 \\
\hline & Reverse & 5'-ATC CGC AGC TCT GAT GTG TTT-3' & 300 \\
\hline \multirow[t]{2}{*}{$\mathrm{I} \kappa \mathrm{B} \alpha$} & Forward & 5'-GCT GAT GTC AAT GCT CAG GA-3' & 300 \\
\hline & Reverse & 5'-CCC CAC ACT TCA ACA GGA GT-3' & 900 \\
\hline \multirow[t]{2}{*}{ Survivin } & Forward & $5^{\prime}$ TGC CCC GAC GTT GCC-3' & 900 \\
\hline & Reverse & 5'-CAG TTC TTG AAT GTA GAG ATG CGG-3' & 900 \\
\hline
\end{tabular}

ing calibrator (NP) $\left(\Delta \Delta C_{\mathrm{T}}\right)$. The quantitation is expressed as $2^{-\Delta \Delta C_{\mathrm{T}}}$ to allow graphical presentation, and is shown as $x$-fold expression of the target gene in CP compared to NP set as 1.

\section{Immunohistochemistry}

Immunohistochemistry was performed on four NP and 14 pancreatic tissues affected by CP with different extents of fibrosis. Serial, $2-\mu \mathrm{m}$-thick cryosections were immediately fixed in ice-cold acetone for $10 \mathrm{~min}$, air-dried and incubated for $1 \mathrm{~h}$ with the following mouse anti-human mAbs: antiRelA (IgG1 isotype), I $\kappa \mathrm{B} \alpha / \mathrm{MAD}-3$ (IgG1 isotype), IKK $\gamma /$ NEMO (IgG1 isotype) and cIAP1 (clone B75-1, anti-IgG1 isotype), all purchased from BD Biosciences (PharMingen, Belgium). For detection of survivin, a polyclonal rabbit anti-human antibody (R\&D Systems, Germany) was used. Bound primary antibody was detected via goat anti-mouse and swine anti-rabbit immunoglobulins, respectively, conjugated to peroxidase-labeled dextran polymer in TrisHCl buffer containing carrier protein (EnVision $^{\mathrm{TM}}$, Dako). 3-Amino-9-ethyl-carbazole (Sigma, St Louis, MA, USA) was used as the substrate. Hematoxylin was used as a counterstain. The monoclonal mouse anti-human TTF1 (clone 8G7G3/1, anti-IgG1 isotype) purchased from Zymed Laboratories (South San Francisco, USA) and rabbit anti-human thyroglobulin obtained from DAKO (Copenhagen, Denmark) were used as irrelevant isotype-matched negative controls.

\section{RelA Transcription Factor Assay}

DNA-binding activity of RelA of the $\mathrm{NF} \kappa \mathrm{B}$ transcription factor family in CM treated with $500 \mathrm{U} / \mathrm{ml}$
IFN $\gamma$ (Roche) and $100 \mathrm{ng} / \mathrm{ml}$ of human recombinant Killer $^{\text {TM }}$ TRAIL (Alexis, San Diego, CA, USA) separately and together for $48 \mathrm{~h}$ was determined using an ELISA-based assay (TransAM Kit ${ }^{\mathrm{TM}}$ ) obtained from Active Motif (Rixensart, Belgium). CM $\left(2 \times 10^{5} /\right.$ well $)$ in a six-well plate were used and each stimulation was performed in triplicate. An equal number of cells kept under identical conditions without the addition of any substance were used as controls. In brief, the nuclear extracts were prepared following the manufacturer's instructions and $5 \mu \mathrm{g}$ of nuclear extract was added to microwells coated with a cold oligonucleotide containing the consensus-binding site for $\mathrm{NF} \kappa \mathrm{B}$. After $1 \mathrm{~h}$ incubation at room temperature, the microwells were washed thrice with washing solution. Antibody directed against phosphorylated RelA was used to label the RelA bound to the oligonucleotide and this was followed by an incubation with a secondary antibody conjugated to horseradish peroxidase. Finally, the results were quantified by a chromogenic reaction. Results were analyzed using the Revelation software (Dynatech) and are given in $\mathrm{pg} / \mathrm{ml}$ as means with standard deviations.

\section{Results}

\section{TRAIL-R Surface Profile of Stimulated CM Cells Corresponds to that of Islets in CP}

Against the background that islet cells are TRAILR1 ${ }^{-}$, TRAIL-R2 ${ }^{-}$and TRAIL-R4 ${ }^{+},{ }^{4}$ we tested human insulinoma cell line CM for TRAIL receptor surface expression. CM cells were constitutively devoid of TRAIL-R1, -R2, -R3 (not shown) and -R4, which is a phenotype corresponding to that of islet cells of NP. ${ }^{4}$ The TRAIL-R profile of CM upon stimulation with TGF $\beta$ (24h), IFN $\gamma(18 \mathrm{~h})$ and TRAIL (6h) mimicked 

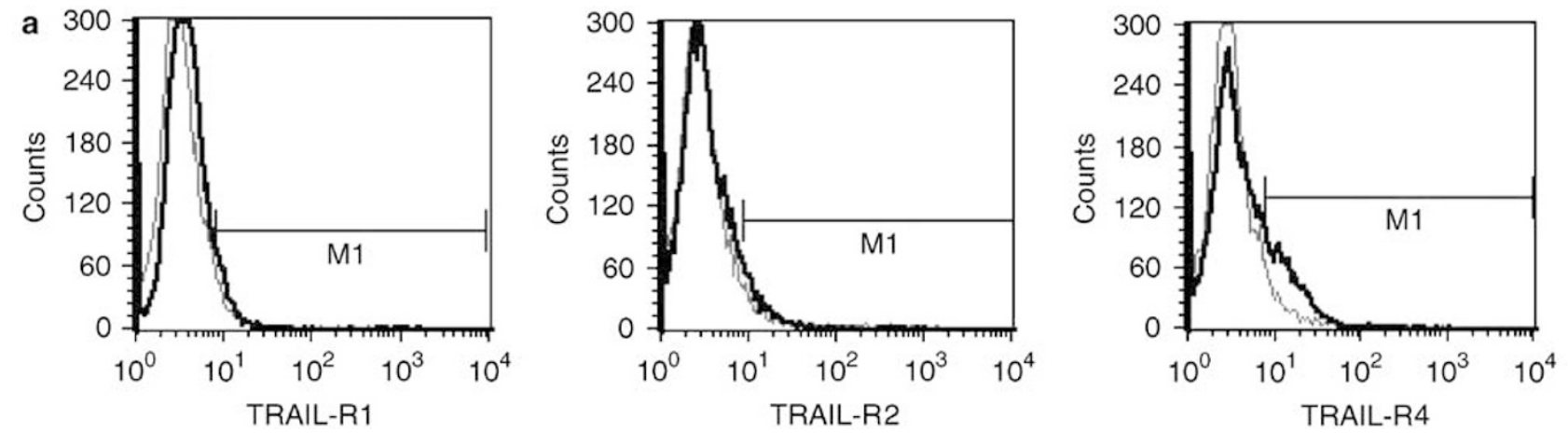

b

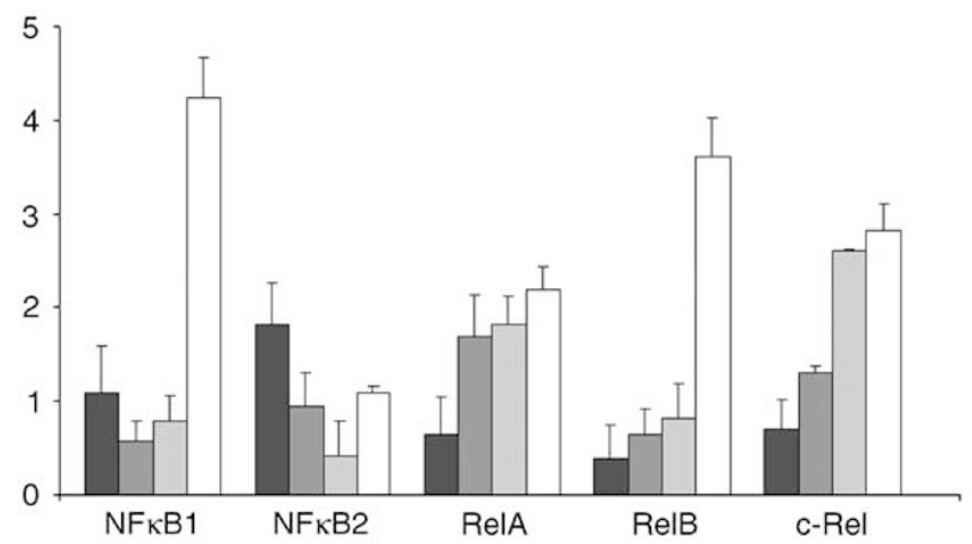

C

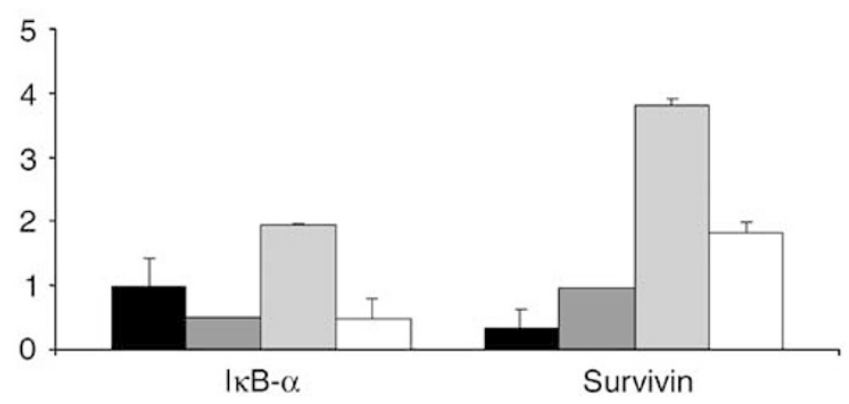

d

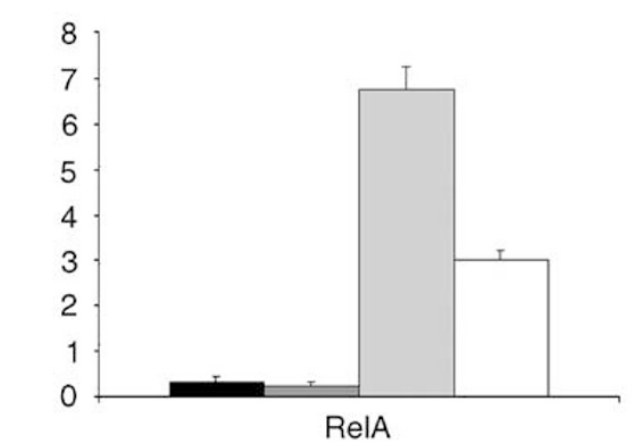

a ctr.

$\square$ TRAIL, 48hrs

IFN $\gamma, 48 \mathrm{hrs}$

$\square$ TRAIL+IFN $\gamma, 48 \mathrm{hrs}$

Figure 1 (a) FACS histograms showing surface expression of TRAIL-R1 (left panel), -R2 (middle panel), and -R4 (right panel) in black lines. M1 marks the subset of CM cells positive for TRAIL-Rs. Isotype-matched negative controls are shown as gray lines. (b) Semiquantitative real-time PCR for $\mathrm{NF} \kappa \mathrm{B}$ subunits in CM cells stimulated for $48 \mathrm{~h}$ with TRAIL, IFN $\gamma$ and TRAIL + IFN $\gamma$ compared with untreated cells. (c) Semiquantitative real-time PCR for NF $\kappa$ B targets $\mathrm{I} \kappa \mathrm{B} \alpha$ and survivin in CM cells stimulated with cytokines for $48 \mathrm{~h}$. $\mathrm{I} \kappa \mathrm{B} \alpha$ mRNA levels increased with IFN $\gamma$, while a decrease was noted with TRAIL and TRAIL + IFN $\gamma$. Survivin mRNA increased considerably with TRAIL, IFN $\gamma$ and TRAIL + IFN $\gamma$. (d) RelA transcriptional activity in CM activated by TRAIL, IFN $\gamma$ and IFN $\gamma+$ TRAIL determined by ELISA compared with untreated control. The bars indicating standard deviation are not always visible due to the minimal variations of values compared to the scale used. 
that of islets in $\mathrm{CP},{ }^{4}$ in being TRAIL-R1-, TRAIL-R2 ${ }^{-}$, TRAIL-R3 $^{-}$(not shown) and TRAIL-R4 ${ }^{+}$in a major subset of cells (Figure 1a).

\section{TRAIL Modulates NFжB Subunit Expression in CM}

Next, CM cells were stimulated with TRAIL, IFN $\gamma$ and TRAIL + IFN $\gamma$ for $48 \mathrm{~h}$ to determine the mRNA expression of $\mathrm{NF} \kappa \mathrm{B}$ subunits and $\mathrm{NF} \kappa \mathrm{B}$ targets $\mathrm{I} \kappa \mathrm{B} \alpha$ and survivin.

The combination of TRAIL and IFN $\gamma$ brought about a four-fold rise in NF $\kappa$ B1 mRNA levels. On the other hand, mRNAs of transcriptionally active $\mathrm{NF} \kappa \mathrm{B}$ subunits RelA, RelB and c-Rel were between two- to 9.5-fold increased compared to untreated cells on TRAIL + IFN $\gamma$ stimulation (Figure 1b). Additionally, mRNA of $\mathrm{NF} \kappa \mathrm{B}$ target $\mathrm{I} \kappa \mathrm{B} \alpha$ was downmodulated, while survivin message increased considerably (Figure 1c).

Thus, TRAIL-R4 acts as a signal transducer in modulating $\mathrm{NF}_{\kappa} \mathrm{B}$ subunits in CM. Moreover, CM did not show sensitivity to TRAIL-mediated apoptosis, as determined by quantifying the sub-1 fraction in FACS, nor did the amount of insulin secretion change significantly under TRAIL treatment (data not shown).

\section{RelA Transcriptional Activity in CM}

The DNA-binding activity of RelA of $N F \kappa B$ family of transcription factors in CM cells as determined by an ELISA-based assay increased significantly following $48 \mathrm{~h}$ stimulation with IFN $\gamma$ (20-fold rise) and TRAIL + IFN $\gamma$ (10-fold) in comparison with untreated control (Figure 1d).

\section{General Aspects in Epithelia of NP and CP}

Turning to tissues, NP had low mRNA levels of $\mathrm{NF} \kappa \mathrm{B}$ subunits. These were increased in $\mathrm{CP}$ in parenchymal areas with fibrosis and most intensely in islets. The expression of $\mathrm{NF} \kappa \mathrm{B}$-regulated proteins $\mathrm{I} \kappa \mathrm{B} \alpha$, survivin and cIAP1 was found in corresponding sites, again at their highest levels in islets surrounded by fibrosis. Specimens from patients with CP were markedly microheterogeneous with respect to each aspect aimed at in this study. As observed in the pilot phase of this study, this heterogeneity seemed to be paralleled not by the degree of inflammatory lymphohistiocytic infiltration but by the degree of fibrosis. Even within the same section, the relative amount of antigen detected was most pronounced in fibrotic areas, the intensity being markedly lower in relatively normal unaffected areas. Therefore, we morphometrically estimated the relative proportion of the stromal and the epithelial compartment in each specimen and defined three grades of fibrosis, that is, mild fibrosis, $12.4 \pm 1.8 \%$, moderate, $41.2 \pm 0.6 \%$, and severe fibrosis, $73.9 \pm 6 \%$; stroma constituted $6.3 \pm 1.9 \%$ of NP (Figure 2).

Cryosections were subjected to LCM to obtain cells from each epithelial compartment of NP and $\mathrm{CP}$ in order to analyze the mRNA expression levels of $\mathrm{NF} \kappa \mathrm{B}$ subunits and stained for proteins for which reliable antibodies were available. Next, we correlated the mRNA levels (data given in Figure 3) and the staining intensities in IHC with the extent of fibrosis (data given in Table 2 and paradigmatic situations depicted in Figure 4). To summarize, NP was largely devoid of expression of $\mathrm{NF} \kappa \mathrm{B}$ constituents, survivin and cIAP1. Message and/or protein levels in pancreatic epithelial compartments increased with the degree of fibrosis. At the extreme, that is, in severe fibrosis, mRNA and/or protein was detected in high amounts, especially in islets spared in the midst of fibrosis.

RelA

In severe fibrosis, there was a sharp increase in RelA transcripts in islet cells but not in acini and ducts (Figure 3). Normal acini, ductal epithelium and islets showed no expression of RelA protein. In CP, RelA protein was detectable and the intensity of staining increased with progressive severity of fibrosis. Staining was most pronounced in the acini and islets in areas of severe fibrosis. In both, the acinar and islet cells, the staining was cytoplasmic and nuclear. The ductal epithelium showed either no or, focally, very low expression of RelA. In CP with severe fibrosis associated with exocrine parenchymal regression, the acini in fibrotic areas featuring a tubular morphology exhibited strong cytoplasmic and nuclear positivity. Pancreatic islets that were intact within severely fibrotic areas stained most intensely for RelA, staining being cytoplasmic as well as nuclear (Figure 4).

\section{$N F \kappa B 1$ (p105)}

There was a sharp, about 10-fold, increase in $\mathrm{NF} \kappa \mathrm{B} 1$ (p105) transcript numbers in islet cells in areas of severe fibrosis (Figure 3). As was the case for $\mathrm{NF} \kappa \mathrm{B} 1$ (p100), no protein data are available for $\mathrm{NF} \kappa \mathrm{B} 2$ (P100), RelB and c-Rel due to the lack of a reliable antibody.

Figure 2 Morphometric analysis of the relative proportion of stromal and epithelial tissue in NP and CP. Three grades of fibrosis, that is, mild fibrosis, $12.4 \pm 1.8 \%$, moderate, $41.2 \pm 0.6 \%$, and severe fibrosis, $73.9 \pm 6 \%$, and NP, $6.3 \pm 1.9 \%$ were calculated by binary analysis of H\&E-stained cryosection (left panel). White areas depict the epithelial compartment, gray areas empty spaces (eg ductal and vessel lumina) and the black areas represent stromal tissue (right panel). 

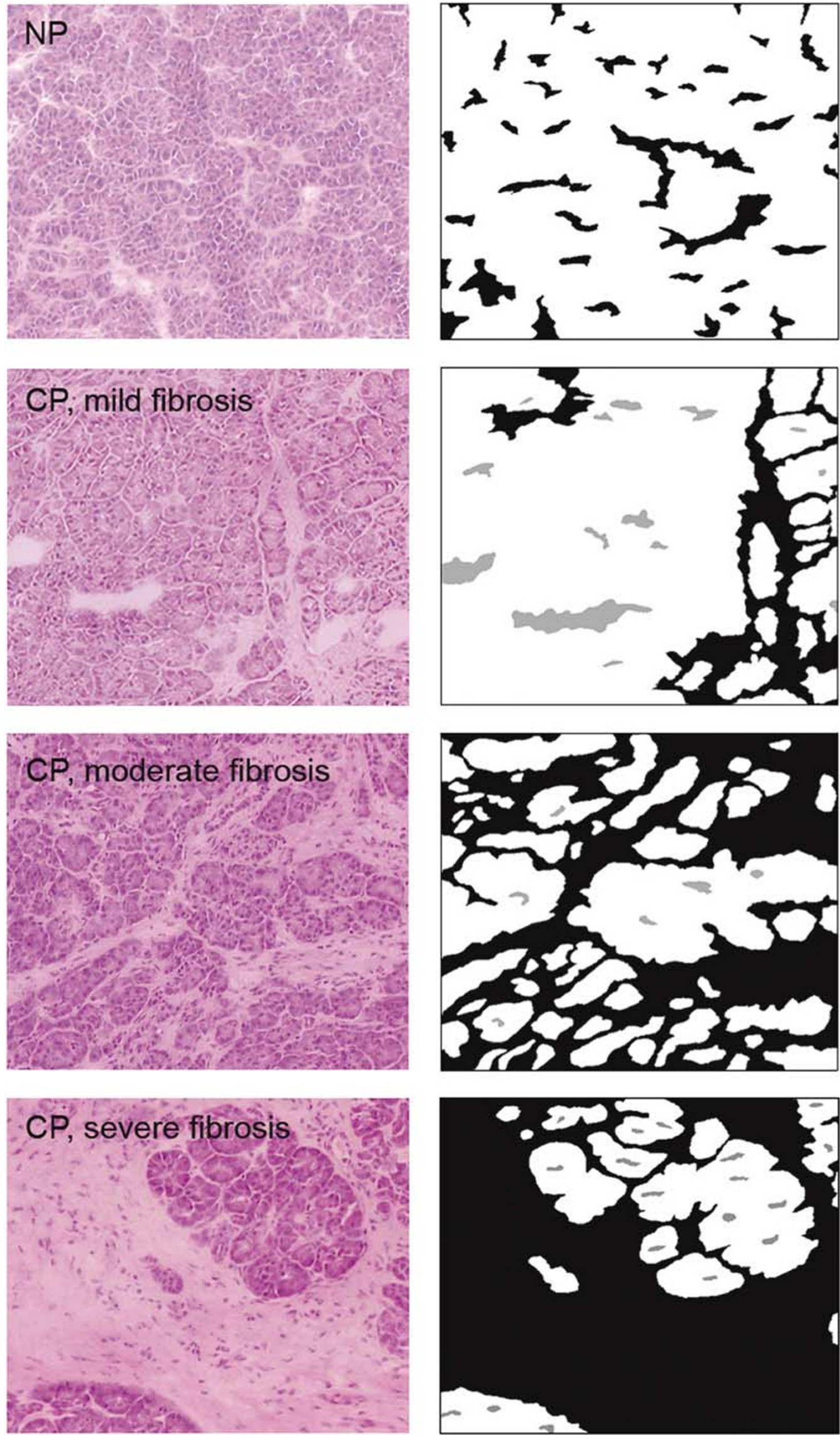

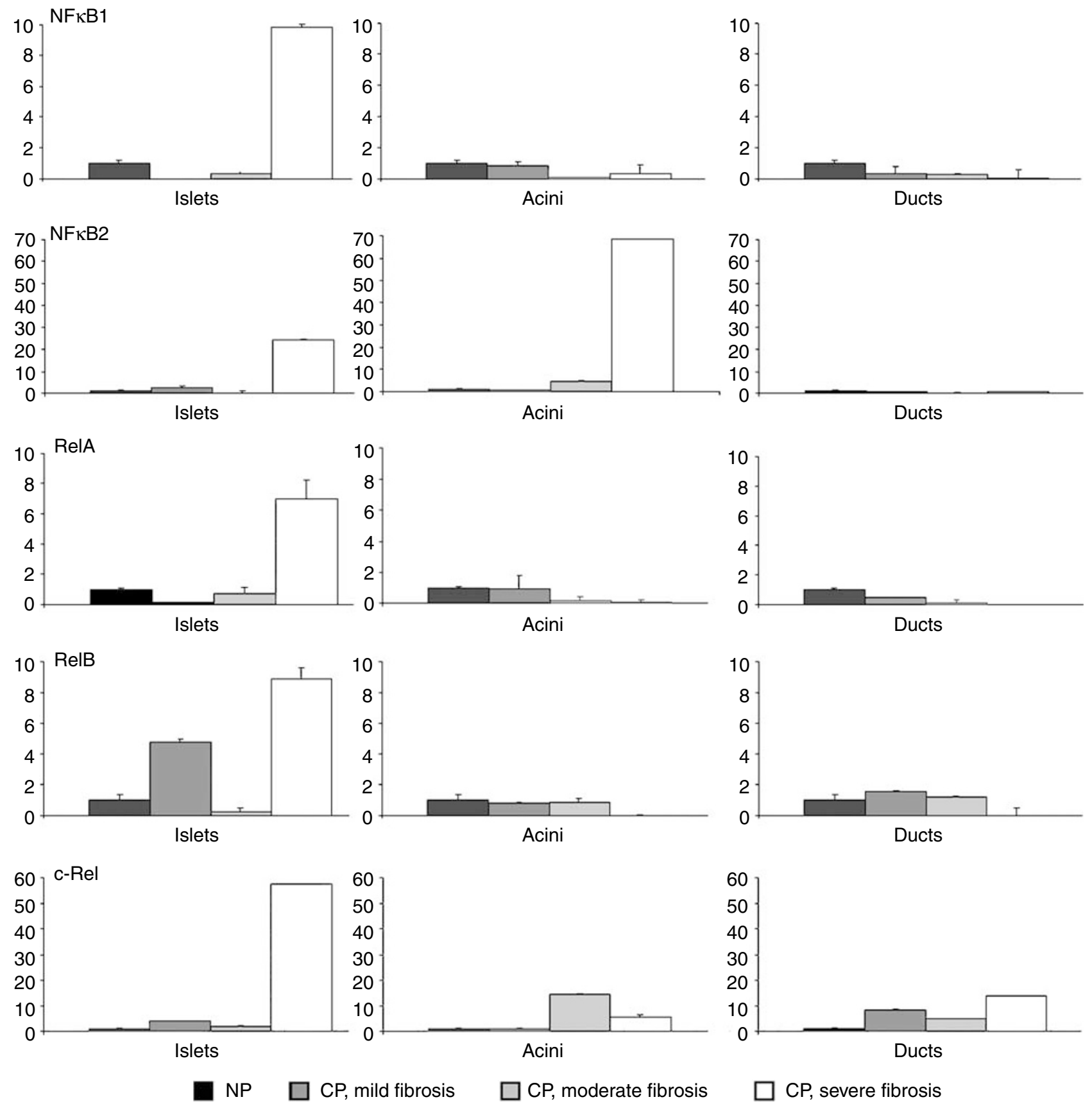

Figure 3 Semiquantitative real-time PCR for $\mathrm{NF} \kappa \mathrm{B}$ subunits. Cyclophilin was used as the internal standard. The diagram depicts the $x$ fold expression of $\mathrm{NF} \kappa \mathrm{B} 1, \mathrm{NF} \kappa \mathrm{B} 2$, RelA, RelB and c-Rel in different microdissected epithelial compartments of CP with mild, moderate and severe fibrosis compared with corresponding epithelial compartments of NP, set as 1, after normalization of the $C_{\mathrm{T}}$ values of each sample to its internal standard. The bars indicating standard deviation are not always visible due to the minimal variations of values compared to the scale used.

$N F \kappa B 2(p 100)$

A similar pattern was observed in $\mathrm{NF} \kappa \mathrm{B} 2$ (p100) mRNA levels with the exception of acinar cells showing 4.6- and 69-fold increase in moderate and severe fibrosis, respectively (Figure 3). Islets showed nearly 24 -fold amount of message in areas of severe fibrosis.

\section{RelB}

RelB mRNA was overexpressed in islet cells in mild and even more so in severe fibrosis (Figure 3).

\section{c-Rel}

In acini and ducts, there was a slight increase in c-Rel mRNA with higher degrees of fibrosis. This 
Table 2 RelA, survivin and cIAP1 expression in NP and CP

\begin{tabular}{|c|c|c|c|c|c|c|c|c|c|c|c|c|}
\hline \multirow[t]{2}{*}{ Compartment } & \multicolumn{3}{|c|}{$N P$} & \multicolumn{3}{|c|}{$C P$, mild fibrosis } & \multicolumn{3}{|c|}{$C P$, moderate fibrosis } & \multicolumn{3}{|c|}{ CP, severe fibrosis } \\
\hline & RelA & Survivin & IAP1 & RelA & Survivin & $I A P 1$ & RelA & Survivin & $I A P 1$ & RelA & Survivin & $I A P 1$ \\
\hline $\begin{array}{l}\text { Acinar cells } \\
\text { Tubular acini }\end{array}$ & - & $-/(+)$ & - & + & $(+) /+$ & + & ++ & ++ & ++ & $\begin{array}{l}+++ \\
+++\end{array}$ & $\begin{array}{l}++ \\
++\end{array}$ & $\begin{array}{c}++ \\
++/+++\end{array}$ \\
\hline Ductal epithelia & - & $-/(+)$ & - & - & + & $(+) /+$ & $-/(+)$ & $+/++$ & $+/++$ & $-/(+)$ & $+/++$ & $+/++$ \\
\hline Islet cells & - & $-/(+)$ & - & + & + & + & ++ & ++ & ++ & +++ & +++ & +++ \\
\hline
\end{tabular}

Absent, -; low, (+); moderate, +; high, ++; very high, +++ antigen density.

enhancement was by far exceeded by the extensive, 58-fold overexpression of c-Rel in islets, occurring in conjunction with severe fibrosis (Figure 3).

$I K K \gamma$

In NP, IKK $\gamma$ protein expression was restricted to some scattered acinar cells.

In CP, an induction of IKK $\gamma$ was observed in the exocrine and endocrine epithelium paralleled by the degree of fibrosis. In specimens showing only mild fibrosis, IKK $\gamma$ expression was restricted to islets; all pancreatic epithelia showed moderate to high immunoreactivity for IKK $\gamma$ in areas with moderate fibrosis. In severe fibrosis, within the remaining endocrine epithelium, IKK $\gamma$ expression was at mild to moderate levels with lower levels in ducts and acini (Figure 4).

\section{$I \kappa B \alpha$}

The IKK $\gamma$ target, $\mathrm{I} \kappa \mathrm{B} \alpha$, was undetectable in NP and in CP with mild and moderate fibrosis. In contrast, tissues affected with severe fibrosis showed expression of $\mathrm{I} \kappa \mathrm{B} \alpha$, this being more pronounced in islets and the surrounding acinar epithelium (Figure 4).

Against the constitutive paucity of RelA transcripts and low activators $\mathrm{IKK} \gamma$ and $\mathrm{I} \kappa \mathrm{B} \alpha$ protein levels in NP, CP was characterized by fibrosisrelated neoexpression and/or partial increase of mainly IKK $\gamma$ and RelA, and less so of $\mathrm{I} \kappa \mathrm{B} \alpha$. The question thus arose as to whether RelA immunohistochemically shown to be translocated to the nucleus (Figure 4) contributes to the remarkably prolonged survival in pancreatic islet cells in the context of CP by inducing antiapoptotic factors, for example, IAPs such as survivin and cIAP1.

\section{Survivin}

In NP, survivin protein expression was absent or at low levels in ductal, acinar and islet cells. In CP, there was a survivin expression, the intensity of which increased with the extent of fibrosis. In CP cases with severe fibrosis, the intact islets exhibited intense cytoplasmic and nuclear staining. The remaining acini and the tubular acini also stained strongly (Figure 4). This pattern closely resembles those of IKK $\gamma, \mathrm{I} \kappa \mathrm{B} \alpha$ and RelA immunoreactivity.

\section{CIAP1}

The staining pattern mostly parallels the ones described above for RelA and survivin. While NP did not stain for cIAP1, the staining could be discerned in acini, ducts and pancreatic islets in a perinuclear cytoplasmic location in CP with mild fibrosis, becoming more pronounced with increasing fibrosis. In CP with severe fibrosis, the intact islets exhibited an intense cytoplasmic and nuclear pattern. The acini spared by the fibrotic process and the tubular acini also stained strongly (Figure 4).

\section{Discussion}

TRAIL-R4 does not transmit a direct death signal but increasing evidence suggests that it activates $\mathrm{NF} \kappa \mathrm{B}$ transcription factors, first demonstrated in $\mathrm{T}$ cells and transfectants. ${ }^{5}$ We show here for the first time that this is also true for a human insulinoma cell line, CM. CM cells essentially lack surface expression of functional death receptors, TRAIL-R1 and -R2, and constitutively express TRAILR4 in a minority of cells. Pretreatment of CM cells with $\mathrm{TGF} \beta$ and IFN $\gamma$ upregulated R4, while R1 and R2 remained unchanged. Treatment of these in vitroactivated cells with TRAIL led to an increase in transcripts for transcriptionally active RelA, RelB and c-Rel subunits together with a slight decrease in mRNA of the generally transcriptionally inactive molecules $\mathrm{NF} \kappa \mathrm{B} 1$ (p105) and $\mathrm{NF} \kappa \mathrm{B} 2$ (p100). Furthermore, this resulted in a downmodulation of $\mathrm{I} \kappa \mathrm{B} \alpha$ and remarkable increase in survivin transcripts. Since TRAIL-R4 is the only functionally expressed TRAIL receptor in CM cells, this TRAIL effect most probably is transmitted via TRAIL-R4. Untreated and IFN $\gamma / \mathrm{TGF} \beta$-stimulated CM cells were resistant to TRAIL-mediated apoptosis. Moreover, TRAIL modulated their $\mathrm{NF} \kappa \mathrm{B}$ repertoire in a way that activated antiapoptotic programs. Further, we found elevations in DNA-binding activity of RelA upon treatment with IFN $\gamma$ and IFN $\gamma+$ TRAIL.

With this, we turned to the in situ analysis of NP and CP. We show that NP is characterized by low expression levels of $\mathrm{NF} \kappa \mathrm{B}$ subunit transcripts in both exocrine and endocrine compartments. In CP, there is a massive induction of $\mathrm{IKK} \gamma$ and $\operatorname{RelA}$ protein, which is at its maximum in islets. Immu- 

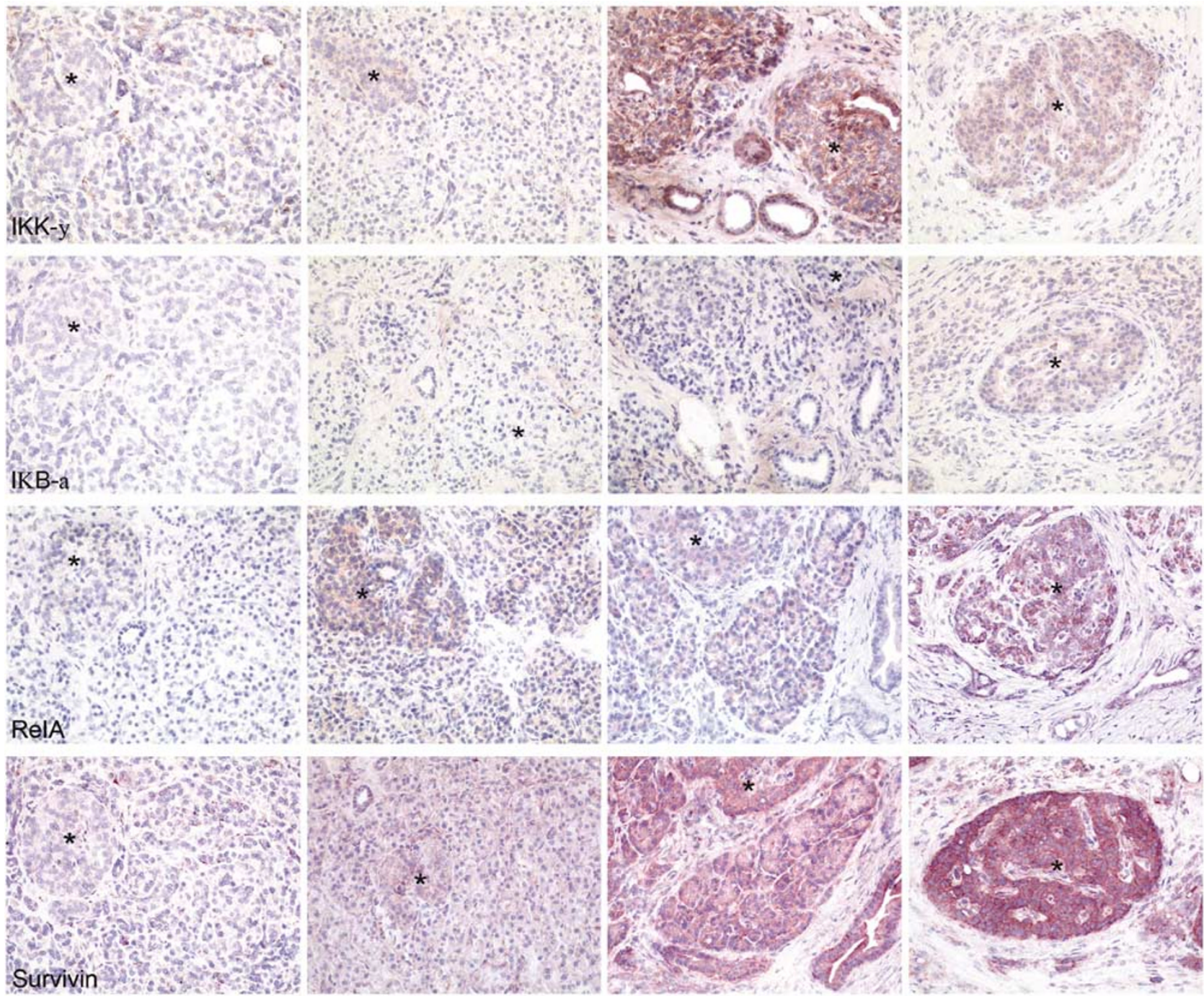

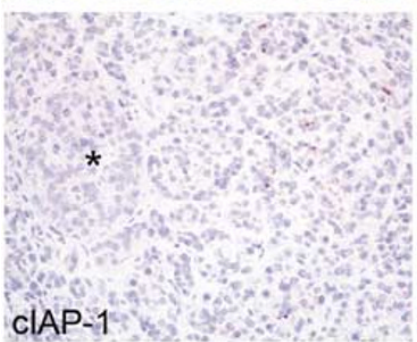

NP

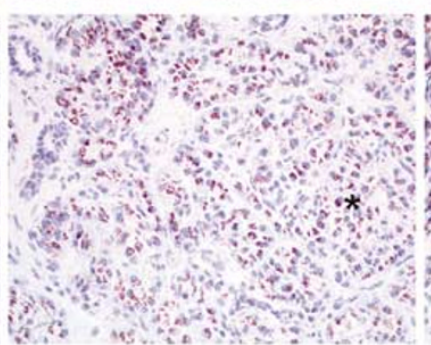

$\mathrm{CP}$, mild fibrosis

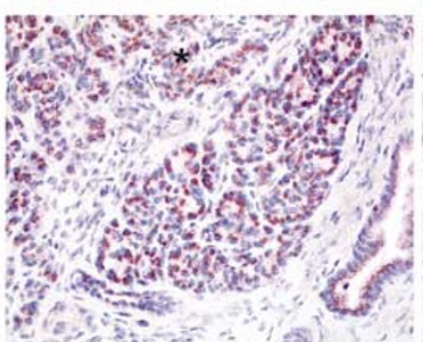

$\mathrm{CP}$, moderate fibrosis

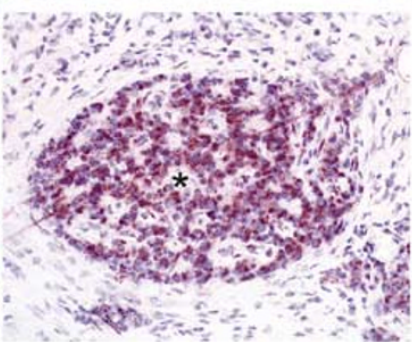

$\mathrm{CP}$, severe fibrosis

Figure 4 Immunohistochemistry for IKK $\gamma, \mathrm{I} \kappa \mathrm{B} \alpha$, RelA, survivin and cIAP1. IKK $\gamma$ : NP tissues show no or only a very weak expression of IKK $\gamma$. Weak expression emerges in islets of mild fibrosis, whereas acini and ducts remain largely negative or exhibit only a weak staining. In CP with moderate fibrosis, there is a marked enhancement in staining intensity in the islets, acini and focally in the ducts; the islets are slightly positive in $\mathrm{CP}$ with severe fibrosis. $\mathrm{I} \kappa \mathrm{B} \alpha$ : NP, CP with mild and moderate fibrosis are largely devoid of $\mathrm{I} \kappa \mathrm{B} \alpha$. In $\mathrm{CP}$ with severe fibrosis, there is a moderate expression in the islets and weakly so in the acini, but none in the ducts. RelA: normal acini, ductal epithelium and islets are devoid of RelA; in CP with mild fibrosis, staining is appreciable in acinar cells and much more intense in islets, while ducts show a very weak or no expression. In CP with moderate fibrosis, the acini and islets exhibit a stronger cytoplasmic positivity. In CP with severe fibrosis, the islets cells show a very strong cytoplasmic and nuclear staining; the remaining acini are also strongly positive. Survivin: acini, islets and ducts in NP express survivin only very weakly; staining is conspicuous in acini, islets and ducts in CP with mild fibrosis. With moderate fibrosis, there is an intense staining of all the epithelial compartments. In severe fibrosis, the islets exhibit further accentuation in the staining intensity in the cytoplasm and the nucleus. cIAP1: acini and ducts in NP do not stain for cIAP1. Staining emerges in the cytoplasm of acinar and islets cells with mild fibrosis; ducts are negative. In moderate fibrosis, there is further accentuation of staining in the acini, islets and staining emerges in ducts. In severe fibrosis, islets exhibit an even stronger reaction; acini and ducts are also stained intensely; staining is cytoplasmic as well as nuclear ( ${ }^{*}$ islets). 
nohistochemistry further suggested that this extent of enhancement might be associated with the degree of fibrosis. Since commercially available antibodies to other $\mathrm{NF} \kappa \mathrm{B}$ subunits failed to meet our quality standards, we had to rely solely on the mRNA levels. Therefore, we first morphometrically assessed the degree of fibrosis and isolated mRNA of microdissected islets, acinar and ductal epithelial cells from corresponding serial sections. The results are clearcut and reflect the pattern observed at the protein level. The second important and unprecedented finding is the fibrosis-associated increase in mRNA for $\mathrm{NF} \kappa \mathrm{B} 1, \mathrm{NF} \kappa \mathrm{B} 2$, RelA, RelB and $\mathrm{c}-\mathrm{Rel}$ in islet cells. Together with our findings that transcriptionally active $\mathrm{NF} \kappa \mathrm{B}$ subunits are upregulated in $\mathrm{CM}$ cells upon TRAIL treatment, this interaction may also play a role in CP. Thus, TRAIL, via TRAIL-R4 broadly expressed in CP, may be one, if not a major, factor bringing about the above scenario. ${ }^{10}$

At present, there is a wealth of data on the defensive and protective role $\mathrm{NF} \kappa \mathrm{B}$ plays in the acute phase response in inflammation. ${ }^{11,12}$ It was suggested that RelA and c-Rel are functional antagonists with respect to apoptosis, RelA overexpession inhibiting apoptosis, while c-Rel acts in a proapototic way by enhancing TRAIL-R1, -R2 or suppressing cIAP1, cIAP2 and survivin. ${ }^{13}$ It was, however, also suggested that $\mathrm{NF} \kappa \mathrm{B} 2$ (p100) might be a direct activator of programmed cell death. ${ }^{14,15}$ $\mathrm{NF} \kappa \mathrm{B}$ was shown to be involved in acute pancreatitis. ${ }^{16}$ Activation of $\mathrm{NF} \kappa \mathrm{B}$ was detected as early as $10 \mathrm{~min}$ after supramaximal stimulation in the cerulein model of acute pancreatitis and seemed to limit the damage induced, while blocking $\mathrm{NF} \kappa \mathrm{B}$ activation had an adverse effect. ${ }^{16}$ Conversely, intraductally administered in vivo gene transfer of RelA led to $\mathrm{NF} \kappa \mathrm{B}$ activation, acinar damage and acute pancreatitis in rats. ${ }^{17}$ Thus, it remains unclear whether $\mathrm{NF} \kappa \mathrm{B}$ activation in pancreas is protective or deleterious. ${ }^{18}$ Remarkably, in the acini of CP with severe fibrosis, we found a 69 -fold $\mathrm{NF} \kappa \mathrm{B} 2$ mRNA expression, eventually tilting the balance in favor of apoptotic cell death in the exocrine compartment.

Our new findings collectively suggest that in CP, a progressive disease smoldering for years, there is a reprogramming of endocrine and, less so, exocrine cells for an altered state of $\mathrm{NF} \kappa \mathrm{B}$-regulated transcriptional activity, the functional consequences of which, at the single-cell level, are largely unclear. One family of genes regulated by $\mathrm{NF} \kappa \mathrm{B}$ are IAPs, acting as suppressors of apoptosis by inhibiting caspase-3, -7 and $-9 .^{9,19}$ It was suggested that cancer cells, for example, of pancreatic carcinoma, ${ }^{20,21}$ can counteract apoptotic signals by the expression of IAPs. We found a pattern of fibrosis-associated enhancement of cIAP1 and survivin protein expression similar to RelA emerge in islets. Our finding of cIAP1 protein being undetectable in NP is at variance with published data suggesting that mRNA is present in all adult tissues. ${ }^{22}$ The low levels or lack of survivin expression in NP is in line with data on the absence of mRNA in normal adult tissues ${ }^{22}$ and the absence of protein in NP reported by Satoh et $a .^{21}$ However, survivin expression has been reported in human fetal islets. ${ }^{23}$ We show for the first time a fibrosis-associated dramatic induction of both cIAP1 and survivin in CP, again, especially in islet cells.

Our findings suggest that sustained enhanced expression of $\mathrm{NF} \kappa \mathrm{B}$ subunits and, consequently, IAPs are lifeguards for endocrine cells in the adverse microenvironment of $\mathrm{CP}$, while the pattern of $\mathrm{NF} \kappa \mathrm{B}$ activation is likely to be deleterious to exocrine parenchyma. One of the key inductors of this reprogramming might be TRAIL. Interestingly enough, TRAIL was shown in two independent experimental studies to protect islet cells in experimental type I diabetes in mice. ${ }^{24} \mathrm{Mi}$ et al reported TRAIL gene upregulation in islet cells during the development of diabetes of nonobese diabetic (NOD) mice. Further, treatment of freshly isolated islet cells with TRAIL did not result in apoptosis. Finally, TRAIL blockade exacerbated the onset of type I diabetes in NOD Scid recipients of transferred diabetogenic $\mathrm{T}$ cells. Lamhamedi-Cherradi et $a 2^{25}$ treated normal and TRAIL-deficient mice with multiple low-dose streptozotocin to induce diabetes. They went on to treat NOD mice with soluble TRAIL blocker. Both the incidence and the degree of insulitis in both disease models were enhanced in the absence, or blockade, of TRAIL. Although both groups of authors attribute the protective TRAIL effect to an inhibition of proliferation of diabetogenic T cells, it seems, against the background of our findings, worthwhile considering TRAIL-mediated protection of the islet cells as an alternative possibility.

The two major epithelial components of pancreas meet different fates in different chronic inflammatory diseases. In CP, where the exocrine parenchyma is progressively lost, the endocrine islets remain intact and functional, even in advanced stages of fibrous replacement. Vice versa, in type I diabetes, the islet cells vanish in the course of insulitis, while the exocrine parenchyma is unaffected. In both processes, apoptotic cell death is the key event. ${ }^{26}$ Current understanding suggests that immune attacks are cell type specific, and there is little left to doubt this. Nevertheless, chronic inflammation functions via local release of chemokines, cytokines and soluble death receptor ligands, which lack the specificity of cognate T-cell-target cell interaction. These short-range acting molecules not only fuel the directed attack but are also likely to inflict collateral damage, ${ }^{27}$ all the more if targets and innocent bystanders are so intimately assembled. Therefore, survival programs run by exocrine and endocrine cells regulating their fate in terms of apoptosis resistance or susceptibility must fundamentally differ in CP and type I diabetes, although the death pathways and their interfering inhibitors are very likely just the same in both cell types. 


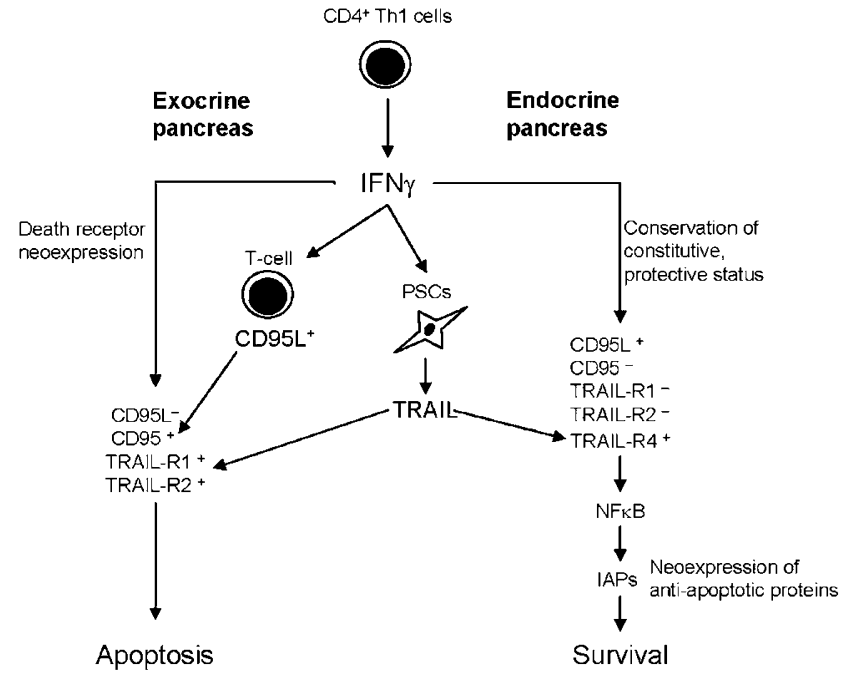

Figure 5 Hypothetical model of dichotomy of fates of pancreatic epithelia in CP.

Summarizing our previous findings ${ }^{3,4}$ and integrating our new data, we propose the following model of CP leading to enforced death of exocrine cells and at the same time to armored survival of endocrine cells (Figure 5). Initiated by IFN $\gamma$ locally released by $\mathrm{CD} 4^{+}$Th1 cells, exocrine pancreatic epithelia lose CD95L and neoexpress the functional death receptors CD95, TRAIL-R1 and TRAIL-R2. This renders them vulnerable to CD95L-mediated T-cell attack and/or to action of soluble TRAIL released by IFN $\gamma$-triggered PSCs. The effects of IFN $\gamma$ and TRAIL on endocrine cells are completely opposite. In the setting of CP, islet cells retain their protective $\mathrm{CD} 95 \mathrm{~L}^{+}$, death receptor ${ }^{-}$state but respond to IFN $\gamma /$ TRAIL via TRAIL-R4 signalling with $\mathrm{NF} \kappa \mathrm{B}$ activation and subsequent neoexpression of IAPs. Thus, islet cells at risk of succumbing to collateral damage caused by local release of deathinducing molecules by the inflammatory infiltrate augment their functional repertoire ensuring survival in a locally adverse environment.

\section{Acknowledgements}

This work was supported by a grant from the Deutsche Forschungsgemeinschaft (DFG) SFB 518/ A13 to P Möller and a grant from the Deutsche Krebshilfe (Str 10-1644-St1) to J Sträter.

\section{References}

1 Bockman DE. Morphology of the exocrine pancreas related to pancreatitis. Microsc Res Technol 1997;37:509-519.

2 Kloppel G, Maillet B. Pathology of acute and chronic pancreatitis. Pancreas 1993;8:659-670.
3 Hasel C, Rau B, Perner S, et al. Differential and mutually exclusive expression of CD95 and CD95 ligand in epithelia of normal pancreas and chronic pancreatitis. Lab Invest 2001;81:317-326.

4 Hasel C, Durr S, Rau B, et al. In chronic pancreatitis, widespread emergence of TRAIL receptors in epithelia coincides with neoexpression of TRAIL by pancreatic stellate cells of early fibrotic areas. Lab Invest 2003;83:825-836.

5 Degli-Esposti MA, Dougall WC, Smolak PJ, et al. The novel receptor TRAIL-R4 induces NF-kappaB and protects against TRAIL-mediated apoptosis, yet retains an incomplete death domain. Immunity 1997;7:813-820.

6 Bachem MG, Schneider E, Gross H, et al. Identification, culture, and characterization of pancreatic stellate cells in rats and humans. Gastroenterology 1998;115:421-432.

7 Kruse ML, Hildebrand PB, Timke C, et al. TGFbeta1 autocrine growth control in isolated pancreatic fibroblastoid cells/stellate cells in vitro. Regul Pept 2000;90:47-52.

8 Aggarwal BB, Bhardwaj U, Takada Y. Regulation of TRAIL-induced apoptosis by ectopic expression of antiapoptotic factors. Vitam Horm 2004;67:453-483.

9 Deveraux QL, Reed JC. IAP family proteins-suppressors of apoptosis. Genes Dev 1999;13:239-252.

10 Ashkenazi A, Pai RC, Fong S, et al. Safety and antitumor activity of recombinant soluble Apo2 ligand. J Clin Invest 1999;104:155-162.

11 Barkett M, Gilmore TD. Control of apoptosis by Rel/ NF-kappaB transcription factors. Oncogene 1999;18: 6910-6924.

12 Schmid RM, Adler G. NF-kappaB/rel/IkappaB: implications in gastrointestinal diseases. Gastroenterology 2000;118:1208-1228.

13 Chen X, Kandasamy K, Srivastava RK. Differential roles of RelA (p65) and c-Rel subunits of nuclear factor kappa B in tumor necrosis factor-related apoptosisinducing ligand signaling. Cancer Res 2003;63: 1059-1066.

14 Wang Y, Cui H, Schroering A, et al. NF-kappa B2 p100 is a pro-apoptotic protein with anti-oncogenic function. Nat Cell Biol 2002;4:888-893.

15 Hacker H, Karin M. Is NF-kappaB2/p100 a direct activator of programmed cell death? Cancer Cell 2002;2:431-433.

16 Steinle AU, Weidenbach $\mathrm{H}$, Wagner $\mathrm{M}$, et al. NFkappaB/Rel activation in cerulein pancreatitis. Gastroenterology 1999;116:420-430.

17 Chen X, Ji B, Han B, et al. NF-kappaB activation in pancreas induces pancreatic and systemic inflammatory response. Gastroenterology 2002;122:448-457.

18 Weber CK, Adler G. From acinar cell damage to systemic inflammatory response: current concepts in pancreatitis. Pancreatology 2001;1:356-362.

19 Tamm I, Wang Y, Sausville E, et al. IAP-family protein survivin inhibits caspase activity and apoptosis induced by Fas (CD95), Bax, caspases, and anticancer drugs. Cancer Res 1998;58:5315-5320.

20 Fulda S, Debatin KM. Sensitization for tumor necrosis factor-related apoptosis-inducing ligand-induced apoptosis by the chemopreventive agent resveratrol. Cancer Res 2004;64:337-346.

21 Satoh K, Kaneko K, Hirota M, et al. Expression of survivin is correlated with cancer cell apoptosis and is involved in the development of human pancreatic duct cell tumors. Cancer 2001;92:271-278. 
22 Verhagen AM, Coulson EJ, Vaux DL. Inhibitor of apoptosis proteins and their relatives: IAPs and other BIRPs. Genome Biol 2001;2 (reviews 3009. 1-10).

23 Liggins C, Orlicky DJ, Bloomquist LA, et al. Developmentally regulated expression of survivin in human pancreatic islets. Pediatr Dev Pathol 2003;6:392-397.

24 Mi QS, Ly D, Lamhamedi-Cherradi SE, et al. Blockade of tumor necrosis factor-related apoptosis-inducing ligand exacerbates type 1 diabetes in NOD mice. Diabetes 2003;52:1967-1975.
25 Lamhamedi-Cherradi SE, Zheng S, Tisch RM, et al Critical roles of tumor necrosis factor-related apoptosis-inducing ligand in type 1 diabetes. Diabetes 2003;52:2274-2278.

$26 \mathrm{Ou} \mathrm{D}$, Metzger DL, Wang X, et al. TNF-related apoptosis-inducing ligand death pathway-mediated human beta-cell destruction. Diabetologia 2002;45: 1678-1688.

27 Nagata S. Apoptosis by death factor. Cell 1997;88: 355-365.

Supplementary Information accompanies the paper on Laboratory Investigation website (http://www. nature.com/labinvest) 